\title{
The prognostic significance of geriatric syndromes and resources
}

\author{
Anna Maria Meyer ${ }^{1} \cdot$ Ingrid Becker $^{2} \cdot$ Giacomo Siri $^{3} \cdot$ Paul Thomas Brinkkötter ${ }^{1,4} \cdot$ Thomas Benzing $^{1,4}$. \\ Alberto Pilotto $^{5} \cdot$ M. Cristina Polidori ${ }^{1}$
}

Received: 14 November 2018 / Accepted: 3 March 2019 / Published online: 25 March 2019

(c) Springer Nature Switzerland AG 2019

\begin{abstract}
Background Geriatric syndromes (GS) do not fit into discrete disease categories and are often underdiagnosed in hospitalized older adults. Geriatric resources (GR) are also not routinely collected in clinical settings, although this may potentiate the beneficial effects of clinical decisions. The prognostic relevance of GS and GR has never been systematically evaluated through clinical tools developed for clinical decision purposes.

Aim To ascertain the impact of common GS and GR on patients' prognosis as assessed by means of the comprehensive geriatric assessment (CGA)-based Multidimensional Prognostic Index (MPI).

Methods One hundred and thirty-five hospitalized patients aged 70 years and older underwent a CGA evaluation with calculation of the MPI on admission and discharge. Accordingly, patients were subdivided in low (MPI-1, score 0-0.33), moderate (MPI-2, score 0.34-0.66), and severe (MPI-3, score 0.67-1)-risk of mortality at 1 month and 1 year. Nine GR and 17 GS were identified and collected accordingly.

Results A lower number of GS and a higher number of GR were shown to be highly significantly correlated with a lower MPI, as well as years of education, grade of care, and number of medications independent of age, sex and number of GS or GR. Underweight and obesity according to the BMI were significantly correlated to higher number of GS. Patients with more GR had a significantly higher chance of being discharged home.

Conclusions The MPI evaluation together with GS and GR in acute care for older patients should be encouraged to improve clinical decision-making.
\end{abstract}

Keywords Comprehensive geriatric assessment (CGA) - Multidimensional prognostic index (MPI) - Aging medicine Geriatric syndromes $\cdot$ Geriatric resources $\cdot$ Grade of care

\section{Introduction}

The aging process of the global population is one of the biggest challenges of the twenty-first century. The latest research predicts that the population of persons over 60 years

Alberto Pilotto and M. Cristina Polidori are equal supervisors.

Electronic supplementary material The online version of this article (https://doi.org/10.1007/s40520-019-01168-9) contains supplementary material, which is available to authorized users.

M. Cristina Polidori

maria.polidori-nelles@uk-koeln.de

1 Department II of Internal Medicine and Center for Molecular Medicine Cologne, University of Cologne, Faculty of Medicine and University Hospital Cologne, Cologne, Germany

2 Institute of Medical Statistics and Computational Biology, University Hospital of Cologne, Cologne, Germany will increase up to $22 \%$ in 2050 . This population segment is the most rapidly growing one, with older patients over 80 years of age increasing at fastest rate [1, 2], and carries

3 Scientific Directorate - Biostatistics, E.O. Galliera Hospital, Genova, Italy

4 CECAD, University of Cologne, Faculty of Medicine and University Hospital Cologne, Cologne, Germany

5 Department Geriatric Care, Orthogeriatrics and Rehabilitation, Frailty Area, E.O. Galliera Hospital, Genova, Italy 
along a great burden of multimorbidity, disability, and health expenditure [3-5].

The mix of multimorbidity, acute diseases, and agerelated changes leads to geriatric syndromes (GS). These are common clinical conditions in advanced age not fitting into discrete disease categories, because they involve multiple underlying factors and organ systems [6]. GS are often underdiagnosed in acute hospital settings, although their effect on quality of life and disability is documented [6]. Underrecognition is due to the perception that GS are "normal" aspects of aging. However, if recognized early, their treatment and prevention can significantly reduce part of the burden of disease, disability, hospitalization, and costs [7]. The identification of GS plays a critical role in predicting health outcomes including functional limitations [8-11] and a growing number of them is being shown to be associated with less education, drug or alcohol abuse, and less life satisfaction [12]. Nevertheless, identifying GS in acute medical settings remains one of the biggest challenges of our time [13].

On the other hand, an apparently relatively good subjective well-being despite physical, cognitive, and social losses [14] might be mediated by factors like resiliency and other psychologic features [15] which are considered, among other factors, geriatric resources (GR) [16]. These pave the way to dignified and independent aging [16, 17], but, in acute medicine, GR are typically neglected, and their collection being commonly left to the fields of nursing care or psychology, if at all $[18,19]$.

The most effective way to uncover older patients' GS and risk factors is the adequate performance of the Comprehensive Geriatric Assessment (CGA) [20], which, in fact, has already shown a strong beneficial influence on older patients' trajectories [21,22]. On the basis of a CGA, the Multidimensional Prognostic Index (MPI) can be calculated [23] which has been identified as the most valid, accurate, and feasible among existing forecast indicators of mortality [23-27]. As the MPI can help healthcare professionals to improve clinical decisions in older patients $[24,26,28]$ and knowledge is limited about the prevalence of and reciprocal interactions between GS and GR, the aim of the present study was to evaluate the relationship of common GS and GR with prognosis as assessed by MPI in older, multimorbid patients admitted to an acute internal setting.

\section{Patients and methods}

\section{Patients}

Between August 2016 and May 2017, 228 patients admitted to the Department II of Internal Medicine of the University Hospital of Cologne, Germany, were consecutively screened. Patients were included if older than 70 years of age, multimorbid (more than two chronic conditions requiring long-term treatment) and giving consent to participate within 2-4 days after admission on the ward. Reasons for exclusion were (1) evaluation point outside of the established time window $(n=39)$, (2) inability to consent $(n=20)$, (3) inability to speak German or speech disorder $(n=18),(4)$ refusal to participate $(n=8),(5)$ prefinal situation or death before recruitment $(n=4)$, and (6) multiple times no possibility to meet the patient for recruitment $(n=4)$. The final sample size included 135 patients.

\section{Assessment of participants}

Information was collected regarding presence of GS, GR and Grade of Care (level of care), nursing needs according to the German nursing care insurance (grade $0-5$, with 0 indicating no dependence [29]), advanced care planning, hospitalization, and falls during the previous 12 months.

GS included incontinence, instability, cognitive impairment, depression or irritability, inanition, sensorial impairment, chronic pain, insomnia, irritable colon, impoverishment, isolation, immobility, polypharmacy, iatrogenic disease, incoherence/delirium, fluid/electrolyte imbalance, and swallowing disorders [6, 30-35] (Supplementary 1). Favourable intellectual, physical, social, and economic resources and good living conditions, motivational, emotional, mnestic, competence-related resources were collected as GR as described previously [5, 18, 19, 36] (Supplementary 1).

The MPI calculation [23] was based on assessments including Cumulative Illness Rating Scale (CIRS) [37], Exton Smith Scale (ESS) [38] for the assessment of pressure ulcer risk, Mini Nutritional Assessment Short Form (MNASF) [39], Katz's Activities of Daily Living (ADL) [40], Lawton's Instrumental Activities of Daily Living (IADL) [41], Short Portable Mental Status Questionnaire (SPMSQ) [42] plus number of drugs administered including over the counter (OTC) drugs and living conditions. Patients were able to provide all needed information except in eight cases in which the proxy respondents delivered details. The MPI is a continuous variable from $0=$ lowest risk to $1=$ highest risk of mortality allowing the allocation into one of three mortality risk grades at 1 month and 1 year after the initial evaluation: MPI-1, 0-0.33 = low risk, MPI-2, 0.34-0.66 = moderate risk, and MPI-3, 0.67-1, severe risk [23].

\section{Registration, participant consent, and ethics}

The study is registered at the German Clinical Trials Register (DRKS00010606) and authors declare that the experiments respect the ethical standards for human experimentation that are stated in the Declaration of Helsinki of 1975, 
as revised in 2000, as well as the national law. The study was approved by the Ethical Committee of the University Hospital of Cologne, Germany, and each patient or proxy respondent signed informed consent.

\section{Statistical analysis}

Descriptive statistics were expressed using absolute number and relative frequencies for description of categorical variables and mean (SD) or median (IQR) for continuous variables.

Table 1 Demographical and clinical characteristics of patient sample according to MPI group

\begin{tabular}{|c|c|c|c|c|c|}
\hline & $\begin{array}{l}\text { Total } \\
N=135\end{array}$ & $\begin{array}{l}\text { MPI-1 } \\
N=33(24.4 \%)\end{array}$ & $\begin{array}{l}\text { MPI-2 } \\
N=87(64.4 \%)\end{array}$ & $\begin{array}{l}\text { MPI-3 } \\
N=15(11.1 \%)\end{array}$ & $p$ value $^{\dagger}$ \\
\hline \multicolumn{6}{|l|}{ Demographic } \\
\hline Female, $n(\%)$ & $52(38.5)$ & $11(33.3)$ & $31(35.6)$ & $10(66.7)$ & 0.072 \\
\hline Age (years), mean (SD) & $78.1(5.1)$ & $76.3(4.1)$ & $79.0(5.1)$ & $77.4(6.5)$ & $0.029 *$ \\
\hline Education (years), mean (SD) & $12.5(4.5)$ & $13.3(4.5)$ & $12.8(4.3)$ & $8.9(4.9)$ & $0.004 *$ \\
\hline Level of educational requirements, median (IQR) & $2(1-3)$ & $2(2-3)$ & $2(1-3)$ & $1(1-2)$ & $0.006^{*}$ \\
\hline Length of hospital stay (days), mean (SD) & $11.3(10.2)$ & $10.0(12.1)$ & $11.3(9.6)$ & $14.3(9.3)$ & 0.090 \\
\hline \multicolumn{6}{|l|}{ GS } \\
\hline Number of GS (max. 17), mean (SD) & $5.4(2.4)$ & $3.6(1.7)$ & $5.5(2.1)$ & $8.5(1.8)$ & $<0.001^{*}$ \\
\hline Polypharmacy, $n(\%)$ & $118(87.4)$ & $22(66.7)$ & $81(93.1)$ & $15(100.0)$ & $<0.001 *$ \\
\hline Instability, $n(\%)$ & $95(70.4)$ & $19(57.6)$ & $65(74.7)$ & $11(73.3)$ & 0.179 \\
\hline Incontinence, $n(\%)$ & $59(43.7)$ & $7(21.2)$ & $40(46.0)$ & $12(80.0)$ & $0.001 *$ \\
\hline Inanition, $n(\%)$ & $56(41.5)$ & $10(30.3)$ & $38(43.7)$ & $8(53.3)$ & 0.254 \\
\hline Immobility, $n(\%)$ & $32(23.7)$ & 0 & $19(21.8)$ & $13(86.7)$ & $<0.001^{*}$ \\
\hline Irritability/depression, $n(\%)$ & $37(27.4)$ & $3(9.1)$ & $26(29.9)$ & $8(53.3)$ & $0.004 *$ \\
\hline Cognitive impairment, $n(\%)$ & $24(17.8)$ & $3(9.1)$ & $16(18.4)$ & $5(33.3)$ & 0.122 \\
\hline Insomnia, $n(\%)$ & $46(34.1)$ & $6(18.2)$ & $30(34.5)$ & $10(66.7)$ & $0.004 *$ \\
\hline Impoverishment, $n(\%)$ & $8(5.9)$ & 0 & $4(4.6)$ & $4(26.7)$ & $0.001 *$ \\
\hline Swallowing disorder, $n(\%)$ & $21(15.6)$ & 0 & $14(16.1)$ & $7(46.7)$ & $<0.001 *$ \\
\hline Chronic pain, $n(\%)$ & $65(48.1)$ & $14(42.4)$ & $42(48.3)$ & $9(60.0)$ & 0.528 \\
\hline Sensorial impairment, $n(\%)$ & $89(65.9)$ & $19(57.6)$ & $58(66.7)$ & $12(80.0)$ & 0.306 \\
\hline Irritable colon, $n(\%)$ & $30(22.2)$ & $5(15.2)$ & $21(24.1)$ & $4(26.7)$ & 0.519 \\
\hline Iatrogenic disease, $n(\%)$ & $19(14.1)$ & $5(15.2)$ & $11(12.6)$ & $3(20.0)$ & 0.735 \\
\hline Social isolation, $n(\%)$ & $13(9.6)$ & $1(3.0)$ & $9(10.3)$ & $3(20.0)$ & 0.169 \\
\hline Fluid/electrolyte problems, $n(\%)$ & $11(8.1)$ & $3(9.1)$ & $5(5.7)$ & $3(20.0)$ & 0.172 \\
\hline Incoherence/delirium, $n(\%)$ & $3(2.2)$ & 0 & $2(2.3)$ & $1(6.7)$ & 0.347 \\
\hline \multicolumn{6}{|l|}{ GR } \\
\hline Number of GR (max. 10), mean (SD) & $5.2(1.9)$ & $6.2(1.7)$ & $5.2(1.7)$ & $3.1(1.6)$ & $<0.001 *$ \\
\hline Physical, $n(\%)$ & $79(58.5)$ & $30(90.9)$ & $48(55.2)$ & $1(6.7)$ & $<0.001 *$ \\
\hline Good living conditions, $n(\%)$ & $92(68.2)$ & $29(87.9)$ & $58(66.7)$ & $5(33.3)$ & $<0.001^{*}$ \\
\hline Social, $n(\%)$ & $116(85.9)$ & $29(87.9)$ & $75(86.2)$ & $12(80.0)$ & 0.532 \\
\hline Economical, $n(\%)$ & $47(34.8)$ & $13(39.4)$ & $33(37.9)$ & $1(6.7)$ & 0.095 \\
\hline Competence-related, $n(\%)$ & $57(42.2)$ & $18(54.6)$ & $39(44.8)$ & 0 & $0.003 *$ \\
\hline Intellectual, $n(\%)$ & $104(77.0)$ & $30(90.9)$ & $64(73.6)$ & $10(66.7)$ & $0.028^{*}$ \\
\hline Spiritual, $n(\%)$ & $45(33.3)$ & $10(30.3)$ & $29(33.3)$ & $6(40.0)$ & 0.542 \\
\hline Motivational, $n(\%)$ & $49(36.3)$ & $16(48.5)$ & $29(33.3)$ & $4(26.7)$ & 0.089 \\
\hline Emotional, $n(\%)$ & $66(48.9)$ & $20(60.6)$ & $42(48.3)$ & $4(26.7)$ & $0.036^{*}$ \\
\hline Mnestic, $n(\%)$ & $46(34.1)$ & $11(33.3)$ & $31(35.6)$ & $4(26.7)$ & 0.819 \\
\hline GR $(\%)>$ GS $(\%), n(\%)$ & $101(74.8)$ & $32(97.0)$ & $66(75.9)$ & $3(20.0)$ & $<0.001 *$ \\
\hline
\end{tabular}

${ }^{\dagger}$ Chi-square or Fisher's exact for frequencies, univariate ANOVA for continuous. Significant at 5\%. $p$ values for association between MPI on admission and LHS were analysed for patients who did not die during hospitalization 
Table 2 Number of GS and GR according to several clinical conditions

\begin{tabular}{|c|c|c|c|c|c|}
\hline & $N(\%)$ & $\begin{array}{l}\text { GS } \\
\text { mean }(\mathrm{SD})\end{array}$ & $p$ value $^{\dagger}$ & $\begin{array}{l}\text { GR } \\
\text { mean }(\mathrm{SD})\end{array}$ & $p$ value $^{\dagger}$ \\
\hline Total & 135 & $5.38(2.378)$ & & $5.19(1.9)$ & \\
\hline \multicolumn{6}{|l|}{ Gender } \\
\hline Male & $83(61.5)$ & $5.08(2.3)$ & \multirow[t]{2}{*}{0.070} & $5.10(1.9)$ & \multirow[t]{2}{*}{0.450} \\
\hline Female & $52(38.5)$ & $5.85(2.5)$ & & $5.35(1.8)$ & \\
\hline \multicolumn{6}{|l|}{ Age (years) } \\
\hline $70-74$ & $38(28.1)$ & $5.21(3.0)$ & \multirow[t]{3}{*}{0.733} & $5.18(2.2)$ & \multirow[t]{3}{*}{0.746} \\
\hline $75-84$ & $85(63.0)$ & $5.39(2.2)$ & & $5.14(1.7)$ & \\
\hline $85+$ & $12(8.9)$ & $5.83(2.0)$ & & $5.58(1.8)$ & \\
\hline \multicolumn{6}{|l|}{ Medications at recruitment } \\
\hline$<3$ & $8(5.9)$ & $3.38(2.56)$ & \multirow[t]{4}{*}{$0.022^{*}$} & $5.50(2.3)$ & \multirow[t]{4}{*}{$0.041 *$} \\
\hline $3-5$ & $11(8.1)$ & $4.55(1.4)$ & & $6.00(1.5)$ & \\
\hline $6-9$ & $49(36.3)$ & $5.29(2.2)$ & & $5.57(1.6)$ & \\
\hline$>9$ & $67(49.6)$ & $5.82(2.5)$ & & $4.75(2.0)$ & \\
\hline \multicolumn{6}{|l|}{ BMI $\left(\mathrm{kg} / \mathrm{m}^{2}\right)$} \\
\hline Underweight $(<18.5)$ & $5(3.7)$ & $8.80(1.9)$ & \multirow[t]{4}{*}{$0.001 *$} & $3.40(1.1)$ & \multirow[t]{4}{*}{0.072} \\
\hline Normal weight (18.5-24.9) & $51(37.8)$ & $5.20(2.3)$ & & $5.24(2.0)$ & \\
\hline Overweight (25.0-29.9) & $38(28.1)$ & $4.63(2.4)$ & & $5.61(1.9)$ & \\
\hline Obesity $(>30.0)$ & $36(26.7)$ & $5.92(2.4)$ & & $4.97(1.6)$ & \\
\hline \multicolumn{6}{|l|}{ Level of educational requirements } \\
\hline 1 & $43(31.9)$ & $5.84(2.6)$ & \multirow[t]{4}{*}{$0.036^{*}$} & $5.00(1.8)$ & \multirow[t]{4}{*}{$0.002 *$} \\
\hline 2 & $54(40.0)$ & $5.63(2.3)$ & & $4.81(1.8)$ & \\
\hline 3 & $26(19.3)$ & $4.77(2.2)$ & & $5.46(1.9)$ & \\
\hline 4 & $12(8.9)$ & $3.92(1.6)$ & & $7.00(1.4)$ & \\
\hline \multicolumn{6}{|l|}{ Physical mobility } \\
\hline Yes & $105(77.8)$ & $4.68(2.0)$ & \multirow[t]{2}{*}{$<0.001^{*}$} & $5.62(1.8)$ & \multirow[t]{2}{*}{$<0.001^{*}$} \\
\hline No & $30(22.2)$ & $7.83(2.1)$ & & $3.70(1.5)$ & \\
\hline \multicolumn{6}{|l|}{ Grade of care } \\
\hline None & $91(67.4)$ & $4.60(1.9)$ & \multirow[t]{5}{*}{$<0.001 *$} & $5.74(1.7)$ & \multirow[t]{5}{*}{$<0.001 *$} \\
\hline 1 & $4(3.0)$ & $6.00(1.2)$ & & $4.50(1.3)$ & \\
\hline 2 & $19(14.1)$ & $6.79(3.0)$ & & 4.05 (1.9) & \\
\hline 3 & $18(13.3)$ & $7.33(2.2)$ & & $4.00(1.7)$ & \\
\hline$\geq 4$ & $3(2.2)$ & $7.33(3.5)$ & & $4.00(1.0)$ & \\
\hline \multicolumn{6}{|c|}{ Hospitalization in the last 12 months } \\
\hline Yes & $95(70.4)$ & $5.75(2.5)$ & $0.005^{*}$ & $4.97(1.9)$ & $0.031 *$ \\
\hline No & $40(29.6)$ & $4.50(1.9)$ & & $5.73(1.7)$ & \\
\hline Falls in the last 12 months & & & & & \\
\hline Yes & $62(45.9)$ & $5.74(2.2)$ & 0.101 & $4.87(1.9)$ & 0.064 \\
\hline No & $73(54.1)$ & $5.07(2.5)$ & & $5.47(1.8)$ & \\
\hline MPI & & & & & \\
\hline 1 & $33(24.4)$ & $3.55(1.7)$ & $<0.001 *$ & $6.24(1.7)$ & $<0.001 *$ \\
\hline 2 & $87(64.4)$ & $5.53(2.1)$ & & $5.15(1.7)$ & \\
\hline 3 & $15(11.1)$ & $8.53(1.8)$ & & $3.13(1.6)$ & \\
\hline Discharge allocation & & & & & \\
\hline Home & $94(69.6)$ & $5.15(2.5)$ & 0.146 & $5.53(1.8)$ & $0.011 *$ \\
\hline Geriatric rehabilitation & $21(15.6)$ & $5.33(1.9)$ & & $4.62(1.9)$ & \\
\hline Transferred to another ward & $14(10.4)$ & $6.57(2.3)$ & & $4.14(1.8)$ & \\
\hline Deceased & $6(4.4)$ & $6.33(2.0)$ & & $4.33(2.5)$ & \\
\hline
\end{tabular}

${ }^{\dagger}$ Chi-square or Fisher's exact for frequencies, univariate ANOVA for continuous. Significant at 5\%. $p$ values for association between MPI on admission and LHS were analysed for patients who did not die during hospitalization 
To see the balance between the occurrence of GS and GR, we took the percentage of the exposed GS (individual's exposed number of GS divided by 17 exposed in total) minus the percentage of the exposed GR (individual's exposed number of GR divided by 10 exposed in total) to see, how many patients relatively have more GR as GS.

To test associations between MPI and demographical and clinical characteristics of the patient sample (Table 1) and between number of GS and GR according to several clinical conditions (Table 2), Chi-square or Fisher's Exact for frequencies and univariate ANOVA for continuous variables were tested after testing for normal distribution. $p$ values for association between MPI on admission and LHS or discharge allocation were analysed for patients who did not die during hospitalization. No adjustments were performed unless otherwise specified.

Odds ratios to express the associations between each GS or GR and MPI score or grade of care were calculated using an ordered logistic regression analysis adjusted for age, sex, and number of GR or GS. All collected GS and GR were inserted in the model for testing the effect of each held constant the others (Figs. 1, 2, 3, 4).

Two-tailed probabilities were reported and a significant level alpha of 0.05 was used.

All analyses were performed using STATA (version 14.1, StataCorp., College Station, TX, USA) software and SPSS
(Statistical Package for Social Sciences, SPSS Inc., Chicago, IL, USA, version 24.0) software.

\section{Results}

\section{Demographics}

The demographic and clinical characteristics of the 135 patients according to MPI group are described in Table 1 .

The median age was 78.1 years and patients with MPI-2 being significantly older than patients with a lower MPI value $(p=0.029)$. Slightly above one-third were women $(38.5 \%)$.

The mean education length was 12.5 years $(\mathrm{SD}=4.5)$ and the median level of educational requirements was 2 (IQR $1-3)$, both being significantly inversely correlated with MPI score $(p=0.004 ; p=0.006)$. The mean length of hospital stay of the patients was 11.3 days $(\mathrm{SD}=10.2$, range 2-72 days) and the length of stay being not significantly associated with the MPI $(p=0.090)$.

\section{Geriatric syndromes}

On average, a patient had $5.4(\mathrm{SD}=2.4)$ of 17 assessed GS; patients with higher MPI displaying significantly higher
Fig. 1 Association of GS and MPI as an ordered logistic regression analysis adjusted for age, sex, and number of GR

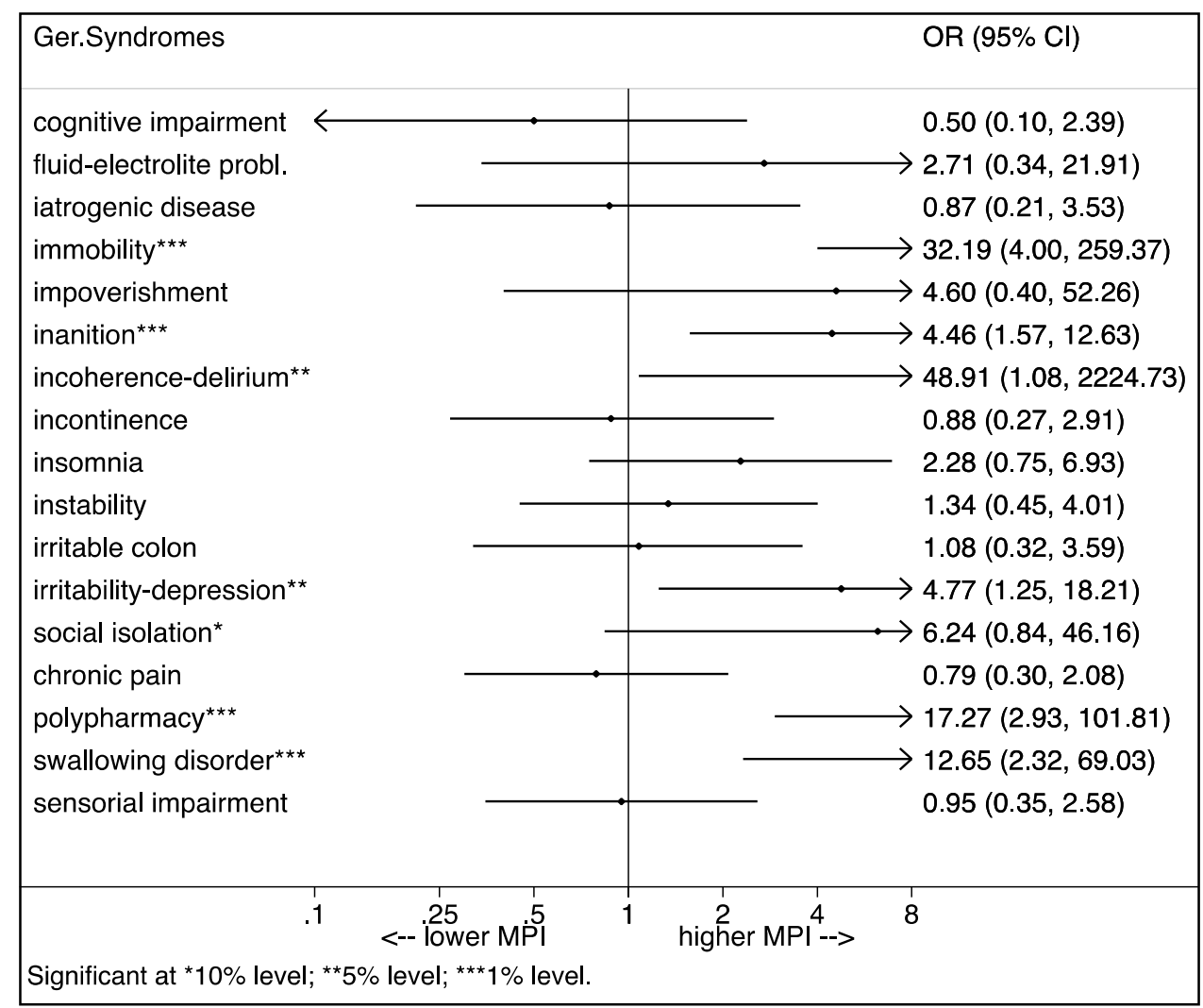


Fig. 2 Association of GR and MPI as an ordered logistic regression analysis adjusted for age, sex, and number of GS
Fig. 3 Association of GS and grade of care as an ordered logistic regression analysis adjusted for age, sex, and number of GR

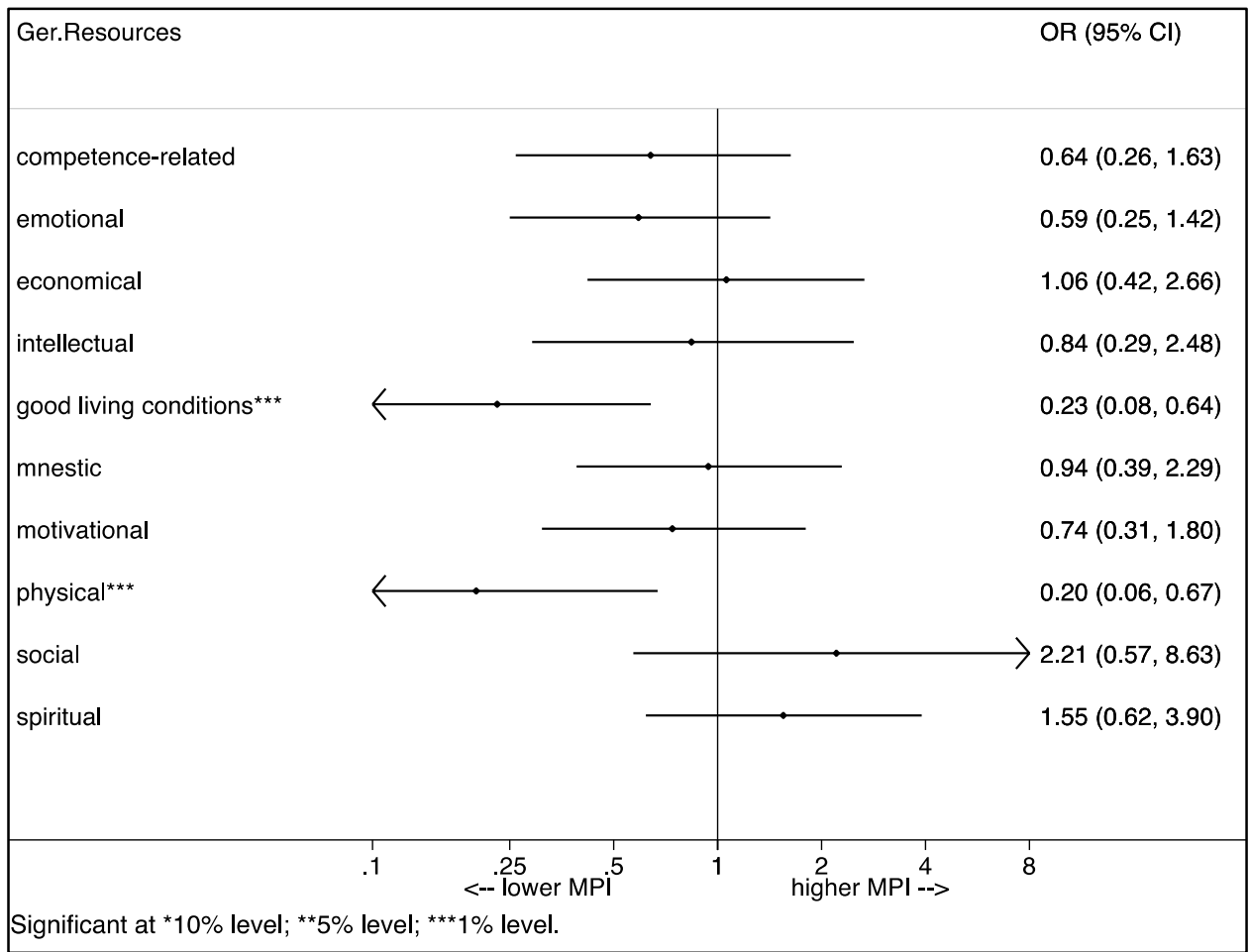



mean number of GS and frequencies of GS are shown in Table 1.
In the explorative univariate analysis, the occurrence of polypharmacy, incontinence, immobility, rather than irritability/depression, insomnia, impoverishment, and 
Fig. 4 Association of GR and grade of care as an ordered logistic regression analysis adjusted for age, sex, and number of GS

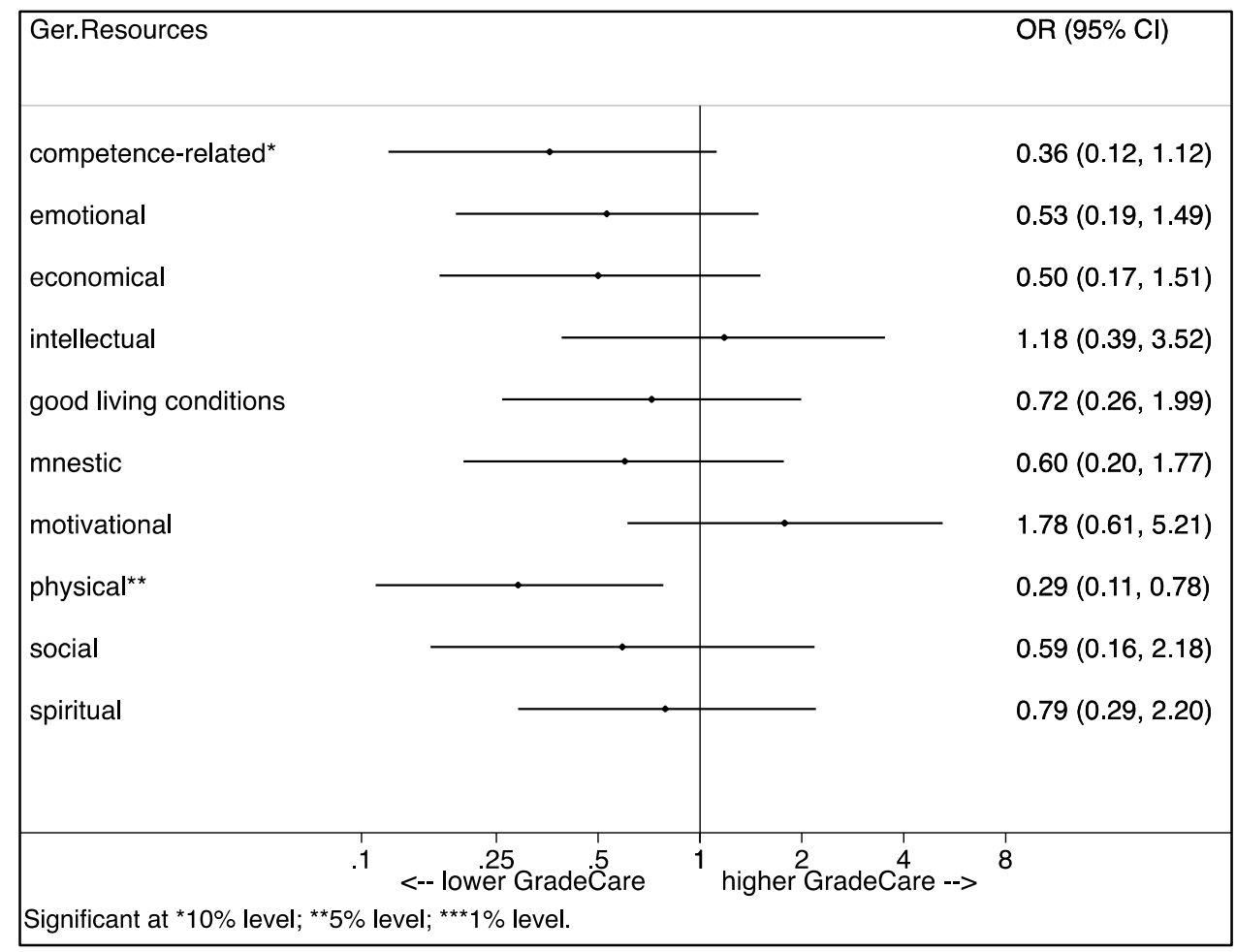

swallowing disorder, was significantly associated with a higher MPI $(p<0.004)$.

The ordered logistic regression model (Fig. 1) shows that specific patterns of GS are associated with the MPI groups. Patients with polypharmacy and inanition, as well as with immobility, delirium, depression, and swallowing disorders had a significantly higher chance of being in a higher MPI group $(p<0.05)$, after adjusting for age, sex, and number of GR, while the adjustment for level of educational requirements did not change the highlighted effects.

\section{Geriatric resources}

On average, the enrolled patients had $5.2(\mathrm{SD}=1.9)$ of 10 assessed GR. Lower MPI values were significantly correlated with a higher average number of GR $(p<0.001)$.

Frequencies of GR are displayed in Table 1. Competence-related resources were significantly associated to a lower MPI as none of the MPI-3 had competence-related resources, but $54.6 \%$ of the MPI-1 group did $(p=0.003)$. In addition, physical, intellectual, and emotional resources were significantly associated with a lower MPI $(p<0.05$; Table 1).

In addition, the resource of good living conditions was highly significantly associated with a lower MPI (MPI-1: $87.9 \% ; p<0.001)$.

After adjusting for age, sex, and number of GS, patients with good living conditions had a significantly lower risk of being in a higher MPI group than patients without this resource $(\mathrm{OR}=0.23, p<0.001)$, given that the other variables are held constant in the model (Fig. 2). This effect is also shown for specific patterns of GR according to MPI groups. The absence of good living conditions and physical resources relates to a severe MPI. On the other hand, these resources plus competence-related and motivational resources are highly present in MPI-1 patients. Likewise, the same effect can be found for the presence of physical resources $(\mathrm{OR}=0.20, p<0.01)$.

\section{Geriatric syndromes and resources}

The prevalence of GS and GR was significantly correlated to each other, patients having more GS displaying less GR and vice versa $(p<0.001)$. The reciprocal relationship between GS and GR was also shown during a percentual analysis, which showed a highly significant relationship between lower MPI scores and GR $>$ GS $(p<0.001)$. In fact, while $20.0 \%$ of the MPI-3 patients had more GR than GS, $75.9 \%$ of the MPI-2 and nearly all patients of MPI-1 (97.0\%) were shown to have more resources than syndromes (Table 1).

\section{Geriatric syndromes, resources, and clinical conditions}

The Body Mass Index (BMI) was shown to be significantly associated with the mean number of GS ( $p=0.001$; Table 2), patients with overweight (BMI included 25.0-29.9) displaying less GS than patients with normal weight, underweight 
and obesity $(p=0.019)$. Patients with obesity and underweight had significantly more GS than patients with normal weight or overweight $(p<0.005)$, while underweight patients had more GS than obese patients $(p<0.001)$.

The level of educational requirements was significantly associated with the number of GS $(p=0.036)$ and GR $(p=0.002)$, while patients with a higher level tended to have significantly more GR and less GS ( $p<0.036$, Table 2$)$.

A higher grade of care value as an indicator of nursing needs was significantly associated with a higher number of GS and lower number of GR $(p<0.001)$. In addition, individual GS like the presence of immobility, insomnia, and social isolation were significantly associated with a higher grade of care $(p<0.05$, adjusted for age, sex and number of GR; Fig. 3). Patients with physical resources had a significantly lower chance for a higher grade of care than patients without physical resources $(\mathrm{OR}=0.29 ; p<0.05 ;$ Fig. 4$)$.

The discharge allocation was significantly correlated with the average number of GR, patients being discharged home having significantly more GR than patients being transferred to another ward ( $p=0.011$; Table 2$)$.

\section{Discussion}

The main result of the present study is that a higher number of GS as well as a lower number of GR assessed in a systematic way are significantly associated with worse individual multidimensional prognosis, measured by means of the MPI-an accurate, specific, sensitive, validated prognostic tool, in older multimorbid adults acutely admitted to an acute internal ward.

GR appear to have great prognostic importance for psychological well-being and self-esteem [14, 15]. Along with early life events and midlife non-medical factors, they play a major role in successful aging $[17,43]$. To our knowledge, this study shows for the first time that especially the GR of good living conditions are associated to a better calculated prognosis. This is very relevant, because living conditions can be influenced through active involvement of relatives, through environmental actions or at a political level. In addition, competence-related, emotional and motivational resources show a strong relationship to better prognosis. These GR are often trained and fostered in quality nursing homes and other geriatric settings.

Another finding of the present investigation was the significant, inverse reciprocal association of GS and GR. To our knowledge for the first time, we performed a percentual analysis to describe the relationship of GS and GR in assumption that the imbalance of having more GS than GR could be conductive for a decompensation of the patient and, on the other hand, having more GR could help to deal with GS and help to be longer in a stable, functional status.
If, on one hand, this might sound intuitive, it implies that these two geriatric profiles are interwoven with each other, and the systematic evaluation of resources and syndromes might uncover specific profiles possibly susceptible of tailored interventions to avoid cascades of poor outcomes. In addition, the prompt identification of protecting factors which intervene on holds in older adults a great potential of saving critical hours/days in accelerating stabilization and/ or recovery as well as avoiding onset of new GS after acute disease or relapse of chronic conditions [10, 11, 44]. Typical examples on actions on GR are those exerted on functional, psychological, emotional, and social reserve.

Within this frame, it is not surprising that older adults with higher education or a higher level of educational requirements according to the International Standard Classification of Occupations (ISCO-08) main groups [45] had more GR and less GS than patients with lower educational status (Table 2). On the other hand, a higher need of care as shown by the grade of care was significantly correlated to higher GS and lower GR (Table 2), suggesting that a structured assessment of GR and GS may substantially implement the measurement of nursing needs.

Assessing protective factors related to self-esteem as well as predispositions for nursing needs may facilitate the communication and the interaction with the patients on concrete problems, thereby improving self-management and, therefore, adherence and compliance with decisions and management. Finally, patients with more GR are significantly more often discharged home, underlining the importance of GR for independent living [17] and prevention of prolonged length of hospital stay. Although we could not show a significant relationship between length of hospital stay and MPI group - we ascribe that to the high deviation - the average length of stay tends to be longer with higher MPI.

Taken together, these findings suggest that the implementation of a routine, feasible evaluation of both GS and GR is an important diagnostic step in the management of older patients admitted to an acute internal ward.

The observations presented above are extremely relevant in light of their association with multidimensional prognosis. It was already shown that GS are important in predicting health outcomes, and that a higher number of GS are associated with lower education, life satisfaction, functional decline, and some chronic diseases [8-12, 44]. Furthermore, the existence of GS profiles with specific multimorbidity patterns, for example, the "induced dependency pattern" with the GS of immobility, incontinence, delirium, and pressure ulcers has already been described [12]. The present study confirms the association of syndromes, typical of hospitalized older multimorbid persons, and resources, allowing better clinical outcomes [16], with the individual multidimensional prognosis as assessed by the MPI. As the MPI can help healthcare professionals to improve clinical 
decisions in older patients by calculating the individual risk group for a patient, the shown association with GS and even more specific GS-patterns for different risk groups may facilitate the early detection of vulnerability to GS.

In conclusion, the present results suggest that the individual combination of GR and GS is highly important in the older hospitalized patient population and that their reciprocal relationship reflects the multidimensional mortality risk as assessed by the MPI. Therefore, implementing the number of GS and GR in clinical decision-making and management of these vulnerable patients might be helpful.

\section{Implications}

- GS and GR are reciprocally connected to health-related outcomes

- GR are associated with a higher level of educational requirements, showing again the importance of good education

- Being significantly connected to prognosis as assessed by the MPI, GS and GR should be co-evaluated

Acknowledgements The results were partly presented at the 2018 annual conference of the German Internal Medicine Society as well as at the 2017 annual conference of the German Geriatrics Society, where the work received the Advancement Award for Interdisciplinary Aging Research of the German Geriatrics Society. The authors are grateful to the patients who took their time during the hospital stay to take part into the study.

Author contributions Conceived and designed the clinical trial: AMM MCP. Performed the experiments: AMM. Analysed the data: AMM IB GS. Wrote the paper: AMM. Conception of the manuscript: AMM MCP. Critical revisions: AMM IB PTB TB AP MCP.

\section{Compliance with ethical standards}

Conflict of interest On behalf of all authors, the corresponding author states that there is no conflict of interest.

Ethical approval All procedures performed in studies involving human participants were in accordance with the ethical standards of the Ethical Committee of the University Hospital of Cologne, Germany (the study is registered at the German Clinical Trials Register: DRKS00010606) and with the 1964 Helsinki declaration and its later amendments or comparable ethical standards.

Informed consent Each patient or proxy respondent signed informed consent.

\section{References}

1. Brocklehurst JC (1997) Geriatric medicine in Britain-the growth of a specialty. Age Ageing 4:5-8
2. Lutz W et al (2008) The coming acceleration of global population ageing. Nature. https://doi.org/10.1038/nature06516

3. Bauer M et al (2009) Hospital discharge planning for frail older people and their family. Are we delivering best practice? A review of the evidence. J Clin Nurs 18:2539-2546

4. Nolte E, Knai C (2015) Assessing chronic disease management in European health systems, Observatory Studies Series, No. 39. European Observatory on Health Systems and Policies, Copenhagen

5. Stuck AE, Iliffe S (2011) Comprehensive geriatric assessment for older adults. BMJ. https://doi.org/10.1136/bmj.d6799

6. Inouye SK et al (2007) Geriatric syndromes: clinical, research, and policy implications of a core geriatric concept. J Am Geriatr Soc. https://doi.org/10.1111/j.1532-5415.2007.01156.x

7. Gill TM et al (2002) A program to prevent functional decline in physically frail, elderly persons who live at home. N Engl J Med. https://doi.org/10.1056/NEJMoa020423

8. Brown RT et al (2013) Factors associated with geriatric syndromes in older homeless adults. J Health Care Poor Underserved. https://doi.org/10.1353/hpu.2013.0077

9. Koroukian SM et al (2016) Combinations of chronic conditions, functional limitations, and geriatric syndromes that predict health outcomes. J Gen Intern Med. https://doi.org/10.1007/s1160 6-016-3590-9

10. Sánchez E et al (2011) Prevalence of geriatric syndromes and impact on clinical and functional outcomes in older patients with acute cardiac diseases. Heart. https://doi.org/10.1136/ hrt.2011.227504

11. van Loon IN et al (2016) The relevance of geriatric impairments in patients starting dialysis: a systematic review. Clin J Am Soc Nephrol. https://doi.org/10.2215/CJN.06660615

12. Clerencia-Sierra M et al (2015) Multimorbidity patterns in hospitalized older patients: associations among chronic diseases and geriatric syndromes. PLoS One. https://doi.org/10.1371/journ al.pone. 0132909

13. Olde Rikkert MG et al (2003) Geriatric syndromes: medical misnomer or progress in geriatrics? Neth J Med 61:83-87

14. Lund Jensen $\mathrm{N}$ et al (2017) The impact of socioeconomic status and multimorbidity on mortality: a population-based cohort study. Clin Epidemiol 9:279-289

15. Turjamaa R et al (2013) Forgotten resources of older home care clients: focus group study in Finland. Nurs Health Sci. https://doi. org/10.1111/nhs. 12037

16. Forstmeier S, Maercker A (2008) Ressourcenorientierte Diagnostik im Alter-Klinische Diagnostik und Evaluation. GeroPsych. https://doi.org/10.5167/uzh-8892

17. Black K et al (2012) Aging in community: mobilizing a new paradigm of older adults as a core social resource. J Appl Gerontol. https://doi.org/10.1177/0733464812463984

18. Baumgärtel F et al (2015) I care Pflege. Georg Thieme Verlag, Stuttgart

19. Berking M, Rief W (2012) Klinische Psychologie und Psychotherapie für Bachelor Band II: Therapieverfahren. Lesen, Hören, Lernen im Web. Springer, Berlin

20. Polidori MC, Pilotto A (2018) The comprehensive geriatric assessment-patient-centred, goal-oriented care. In: RollerWirnsberger R, Singler K, Polidori MC (eds) Learning geriatric medicine. Springer, Berlin

21. Martin F (2010) Comprehensive assessment of the frail older patient. Publishing EUGMS, http://www.eugms.org/fileadmin/ user_upload/News_Documents/Publications/Comprehensive Assessment_of_the_Frail_Older_Patient.pdf. Accessed 26 June 2018

22. Rubenstein LZ et al (1984) Effectiveness of geriatric evaluation unit. A randomized clinical trial. N Engl J Med 311:1664-1670 
23. Pilotto A et al (2008) Development and validation of a multidimensional prognostic index for one-year mortality from comprehensive geriatric assessment in hospitalized older patients. Rejuvenation Res 11:151-161

24. Bureau ML et al (2017) Using a multidimensional prognostic index (MPI) based on comprehensive geriatric assessment (CGA) to predict mortality in elderly undergoing transcatheter aortic valve implantation. Int J Cardiol 236:381-386

25. Dent $\mathrm{E}$ et al (2016) Frailty measurement in research and clinical practice: a review. Eur J Intern Med 31:3-10

26. Meyer AM et al (2018) New associations of the Multidimensional Prognostic Index. Z Gerontol Geriat. https://doi.org/10.1007/ s00391-018-01471-6

27. Warnier RM et al (2016) Validity, reliability, and feasibility of tools to identify frail older patients in inpatient hospital care: a systematic review. J Nutr Health Aging 20:218-230

28. Pilotto A et al (2012) Usefulness of the multidimensional prognostic index (MPI) in the management of older patients with chronic kidney disease. J Nephrol 25:79-84

29. Baake CP (Hrsg) (2017) Begutachtungsverfahren NBAPflegegrad bei Erwachsenen. Walhalla Fachverlag, Regensburg

30. Bollheimer C et al (2014) Praxishandbuch Altersmedizin. Kohlhammer Verlag, Stuttgart

31. Kane RL et al (2012) The association between geriatric syndromes and survival. J AM Geriatr Soc. https://doi.org/10.111 $1 / \mathrm{j} .1532-5415.2012 .03942$

32. Neubart R (2015) Repetitorium Geriatrie: Geriatrische Grundversorgung-Zusatz-Weiterbildung Geriatrie-Schwerpunktbezeichnung Geriatrie. Springer, Berlin, pp 175-176

33. Niederfranke A et al (2013) Funkkolleg Altern 1: Die vielen Gesichter des Alterns. Springer, Berlin, pp 301-305

34. Senn N, Monod S (2015) Development of a comprehensive approach for the early diagnosis of geriatric syndromes in general practice. Front Med. https://doi.org/10.3389/fmed.2015.00078

35. Wehling M, Burkhardt H (2016) Arzneitherapie für Ältere. Springer, Berlin
36. Diegelmann C, Isermann M (2016) Ressourcenorientierte Psychoonkologie: Psyche und Körper ermutigen. Kohlhammer Verlag, Stuttgart

37. Linn BS et al (1968) The cumulative illness rating scale. J Am Geriatr Soc 16:622-626 (20-30)

38. Bliss MR et al (1966) Mattresses for preventing pressure sores in geriatric patients. Mon Bull Minist Health Public Health Lab Serv 25:238-268

39. Sancarlo D et al (2011) Validation of a modified-Multidimensional Prognostic Index (m-MPI) including the Mini Nutritional Assessment Short-Form (MNA-SF) for the prediction of one-year mortality in hospitalized elderly patients. J Nutr Health Aging 3:169-173

40. Katz $\mathrm{S}$ et al (1970) Progress in the development of an index of ADL. Gerontologist 10:20-30

41. Lawton MP, Brody EM (1969) Assessment of older people: selfmaintaining and instrumental activities of daily living. Gerontologist 9:179-186

42. Pfeiffer E (1975) A short portable mental status questionnaire for the assessment of organic brain deficit in elderly patients. J Am Geriatr Soc 23:433-441

43. Evert J et al (2003) Morbidity profiles of centenarians: survivors, delayers, and escapers. J Gerontol A Biol Sci Med Sci 58:232-237

44. Yang DC et al (2015) Association between multiple geriatric syndromes and life satisfaction in community-dwelling older adults: a nationwide study in Taiwan. Arch Gerontol Geriatr. https://doi. org/10.1016/j.archger.2015.02.001

45. Züll C (2015) Berufscodierung. Mannheim, GESIS-Leibniz Institut für Sozialwissenschaften (GESIS Survey Guidelines). https://doi.org/10.15465/gesis-sg_019

Publisher's Note Springer Nature remains neutral with regard to jurisdictional claims in published maps and institutional affiliations. 